\title{
Fluorescent Assay Infectious Dose 50 Percent per Dose
}

National Cancer Institute

\section{Source}

National Cancer Institute. Fluorescent Assay Infectious Dose 50 Percent per Dose. NCI

Thesaurus. Code C68882.

A unit of potency expressed as a number of 50 percent infectious doses as defined in the particular fluorescent assay method per dose of preparation. 